https://doi.org/10.48009/1_iis_2005_378-385

\title{
ISOLATION FEELINGS IN DOCTORAL PROGRAMS: A CASE STUDY
}

\author{
Frederick Kohun, Robert Morris University, kohun@rmu.edu \\ Azad Ali, Butler County Community College, azad.ali@bc3.edu
}

\begin{abstract}
The attrition rate among doctoral students is a problem that has been well documented. Numerous studies have been devoted to investigate the reasons for early exit among doctoral students. The isolation feeling that is often felt by doctoral students has been cited as one of the primary reasons for attrition in doctoral programs. This paper is a study to show the effect of isolation among doctoral students. It uses one doctoral program in Information Systems and Communications as a case study to: establish a hypothesis based on the literature on attrition in doctoral programs, take data collected from survey questions distributed to students currently enrolled in this doctoral program, and then analyze data from the survey questions to accept or reject the hypothesis.
\end{abstract}

Keywords: Doctoral Programs, Isolation Feelings in Doctoral Programs, IS Doctorates

\section{INTRODUCTION}

Attrition rates among doctoral students have been a long-standing problem facing graduate programs. Different studies have been conducted to address the issue of retention and various suggestions have been made to minimize the number of students leaving doctoral programs prior to completion. Among the reasons that were cited as a primary cause for early withdrawal from doctoral programs is the feeling of isolation [2].

The doctoral program of Information Systems and Communications (DISC) at Robert Morris University (RMU) has been able to achieve a graduation rate among their students that is substantially higher than the national average. Over the first five years (since its inception), this program graduated three cohorts of students. A total of 38 out of 44 student (or $86 \%$ ) finished their doctoral degree in this program after three years from starting it. When compared to the national average in which less than half of the students who start doctoral programs finish it, the difference in graduation rates is significant [4].

This paper uses this DISC program as a case study to investigate the affect of the feeling of isolation has on graduation rates among doctoral students. It further suggests the role of program structure and design in successful student graduation rates. To achieve this purpose, survey questions were distributed to students of three different cohorts currently enrolled in the DISC program. The first part of the paper reviews literature that discusses attrition reasons among doctoral students. This literature review becomes the basis for the hypothesis on the effect of isolation on doctoral attritions. Later, data collected from the survey is analyzed and discussed in the context of program structure aimed at addressing the issue of the feeling of isolation among doctoral students. 


\section{DOCTORAL ATTRITION - REASONS}

Attrition rate among students entering doctoral programs has been the subject of discussion in various studies. While there are no national statistics that measure the rate of attrition among doctoral students, a number of studies put the number of departing students from doctoral programs prior to completing it at 50\%. Nevertheless, although the rate of attrition varies by program or by location of the university offering the program, the $50 \%$ rate of dropouts remained commonly cited in the different studies [3].

Doctoral faculty initially placed the blame of attrition on the students exiting the program. They cited reasons such as lack of preparation on the part of the students. The feeling among the same faculty is that those students "most able" complete the program while those "less able" drop out. They cite reasons such inadequate training on research during the undergraduate. Doctoral faculty then suggested strengthening the admission requirements of the program thinking that if they admit only the best students then they would be able to attain a higher rate of graduation [2].

Further research however, challenged the under prepared student reasons for attrition. Most of the students who enter doctoral programs are high-achievers that may rarely if ever experienced failures in their lives. At least one survey conducted, tested the effect of undergraduate training on graduate attrition and found out that there is no significant difference in the undergraduate GPA of the students who drop out versus the students who stay in the program [3]. Further, the $50 \%$ rate of attrition remained prevalent despite various attempts to "strengthen" the admission requirements to the doctoral program [2].

This high and continuous rate of attrition indicates, if anything, that factors extend beyond the "ability" of the student contributes to withdrawal from doctoral programs. Other studies that delved into this issue of attrition found factors related to the feeling of isolation among doctoral students significantly contributed to decisions to leave programs. The same studies found that most doctoral programs do not adequately address the integration of students into their academic and social culture [2].

\section{ISOLATION FEELINGS IN DOCTORAL PROGRAMS}

The undergraduate and graduate higher education system contains two subsystems: the academic subsystem and the social subsystem. Colleges and universities that work to integrate students into these subsystems can be shown to increase their chances of success [1]. The integration into the academic subsystem is accomplished by having students taking courses together, talking to other students about courses, and communicating about the academic requirements of the program. Integration into the social subsystem, though not a requirement in the academic arena, is an important determinant in the decision to complete the program or not. Failure to integrate into the social system of the program can lead to dissatisfaction with the program and in the case of doctoral programs; influences the decision to leave [3].

The social subsystem differs widely between graduate and undergraduate programs. Undergraduate programs are filled with social activities that are aimed at integrating the students into the social life within the college/university so to minimize the feeling of isolation. 
Undergraduate programs usually incorporate activities such as orientations, social clubs, and competitive sports to help integrate students into the social life of the college/university/department. The social events for undergraduate programs may not help graduate students in the same way. Most graduate students have already gone through such an experiences as undergraduates and repeating the same things they did before may not be very enticing or help to bring them into the social life of the program they are enrolled.

The requirements of doctoral programs in many cases are not clearly spelled out, thus some students enter a program without knowing all that is required [3]. In many cases they learn the nuances of the program from informal communication with their peers. This is where the social life plays a part in helping the students cope with the difficulties of completing a doctoral program: The students who communicate and socialize with their peers can exchange stories and share experiences about the various issues and how they dealt with them. For the less social person, this feedback becomes less available. As a result there is confusion about work and progress in the program that can lead to greater isolation, potentially bitter feelings and eventually, withdrawal from the program.

The role of communication with the faculty - especially with the faculty advisor becomes an acute issue-especially during the dissertation stage. During this late stage, the students will be compartmentalized into dealing primarily with their faculty advisor. The students become dependent on the advisor for solving issues regarding their work. Thus, conflicts that may arise need to be communicated between the student and the advisor. If there is little communication between the two sides, their relationship deteriorates and the isolation feeling deepens increasing the chance of drop out.

Barbara Lovitts, an author of a book that deals with the effect and consequence of attrition in doctoral programs, is forceful about the effect of isolation on attrition. She emphasizes the relationship between completing the task and social support by saying "The survey show a high correlation between integration into a department's social and professional life (becoming part of the community) and successful completion of the Ph.D. [2, P.3]" Also, in her study, she discusses "the relationship between the type of support students receive, their degree of participation in the department's intellectual and social life and in the profession and their success at completing the Ph.D." [P.3]. Then she further noted, that if departments want to lower attrition rates among their students, they have to integrate socialization events into their programs to break the isolation feeling before it begins.

\section{The Hypothesis}

The literature mentioned above clearly reveals the extent that the feeling of isolation among doctoral students influences the decision to exit early from the program. This paper intends to validate these findings through a series of hypotheses and statistical analysis. The first hypothesis is intended to show the effect of isolation on attrition rate.

Hypothesis Set \#1:

$\mathrm{H}_{0}$ : Isolation feeling among doctoral students is not a contributing factor in attrition among doctoral students. 
$\mathrm{H}_{1}$ : Isolation feeling among doctoral students is a contributing factor in attrition among doctoral students.

As noted earlier in the previous section, the department that promotes social integration into the program has a better chance of lowering attrition rates among their students. This paper further identifies the communication that goes on among the students and also between the students and the faculty. Thus it made the following two set of hypothesis.

Hypothesis Set \#2:

$\mathrm{H}_{0}$ : Creating a system that encourages student-to-student communication does not minimize Isolation feelings among students in doctoral programs.

$\mathrm{H}_{1}$ : Creating a system that encourages student-to-student communication can minimize Isolation feelings among students in doctoral programs.

Hypothesis Set \#3:

$\mathrm{H}_{0}$ : Creating a system that encourages student-to-faculty communication does not minimize Isolation feelings among students in doctoral programs.

$\mathrm{H}_{1}$ : Creating a system that encourages student-to-faculty communication can minimize Isolation feelings among students in doctoral programs.

\section{The Sample}

This paper selected the students attending the doctoral program of Information Systems and Communication at Robert Morris University as a sample for the data collection for this survey. There are three concurrent cohorts that attend this program. Each cohort has its own group of students that attend together, take courses together and supposedly complete the program together. The survey questions were passed to 53 students in the 3 cohorts that are concurrently attending the program. Each student that received the survey has completed at least on semester in the program; thus they are familiar with the program structure, the social system, and the cohort integration part of the program.

\section{The Questions}

Based on the hypotheses made above, a set of questions has been devised in order to conduct the survey and to test the hypothesis. Table 1 below lists the questions that were introduced in this survey. Each question is related to one or more of the hypothesis listed above. Question 1 is directly related to first set of hypothesis. Questions 2, 3, 4, 5, 6, 8, and 10 are related to hypothesis set \#2, while questions 4, 7, 8 and 9 are related to hypothesis \#3. Each question is worded in a way to reflect the finding mentioned in the literature discussed in the previous section. 
Table 1. Survey Questions

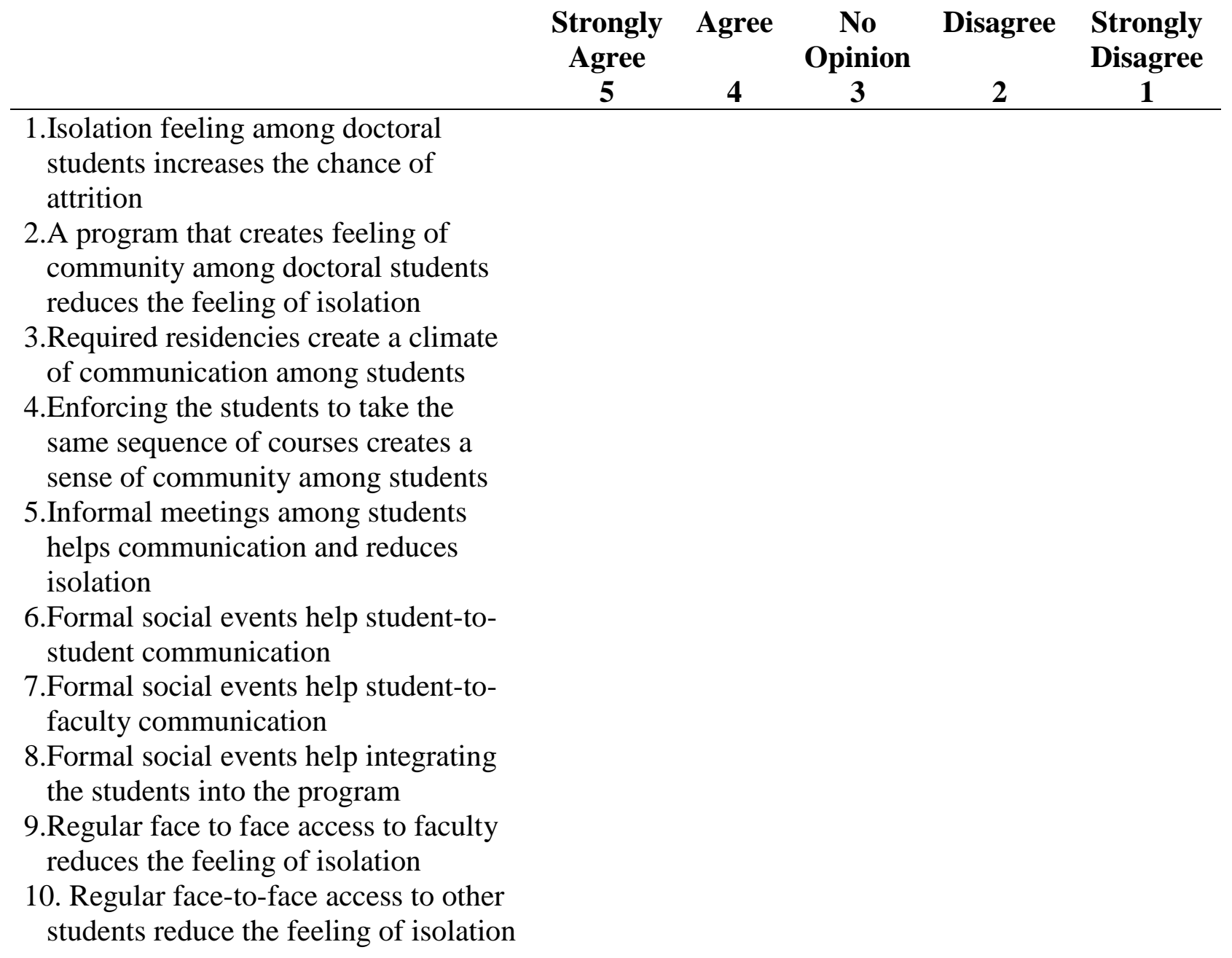

\section{ANALYSIS OF DATA}

Data collected in this survey and entered into SPSS table. Ten variables are identified first, each variable represent a question asked in the survey. Five values are specified that range from 1 to 5. 53 cases were entered into the table, each case represent answers from one student participated in the survey. Chi-Square was run for each of the variables and the results are discussed in the remainder of this section as related to each hypothesis.

Hypothesis \#1: There was only one question related to this hypothesis, the first question. The Chi-Square of 29.170, the N (expected value) is 10.6. Since the observed Chi-Square is significantly above the expected value, there is enough evidence to accept the alternative hypothesis and reject the null hypothesis.

Hypothesis \#2: There were 7 questions related to this hypothesis: 2, 3, 4, 5, 6, 8 and 10. Table 2 below shows the one-sample test results for these questions. 
Table 2. Hypothesis \#2 Data Analysis Summary

\begin{tabular}{cccc} 
Question \# & Degrees of Freedom & Expected Frequency & Chi-Square Value \\
\hline 2 & 3 & 13.3 & 36.887 \\
3 & 3 & 13.3 & 42.925 \\
4 & 4 & 10.6 & 29.547 \\
5 & 3 & 13.3 & 38.396 \\
6 & 4 & 10.6 & 67.094 \\
8 & 4 & 10.6 & 26.340 \\
10 & 3 & 13.3 & 29.038
\end{tabular}

As can be seen from the table above, all the Chi-Square values are above the expected value, thus, there is enough evidence to reject $\mathrm{H}_{0}$ in favor of $\mathrm{H}_{1}$.

Hypothesis \#3: There were 4 questions related to this hypothesis: 4, 7, 8 and 9. Table 3 shows the one-sample test results for these questions.

Table 3. Hypothesis \#3 Data Analysis Summary

\begin{tabular}{cccc} 
Question \# & Degrees of Freedom & Expected Frequency & Chi-Square Value \\
\hline 4 & 3 & 10.6 & 29.54 \\
7 & 3 & 13.3 & 33.566 \\
9 & 3 & 13.3 & 35.830
\end{tabular}

As can be seen from the table above, all the Chi-Square values are all above the expected value, thus, there is enough evidence to reject $\mathrm{H}_{0}$ in favor of $\mathrm{H}_{1}$. Based on the analysis of the data collected, these findings support what was mentioned in the literatures; namely,

1. Isolation feeling among doctoral students is a factor influences attrition rate.

2. Isolation feeling can be minimized through incorporating social activities within the program that encourage student-to-student communications.

3. Isolation feeling can be minimized through incorporating social activities within the program that encourage student-to-faculty communications

\section{THE DISC PROGRAM AT RMU}

The Doctoral program of Information Systems and Communications at Robert Morris University started in 1999 and is designed in such a way that it intends to minimize the main source of attrition among doctoral students: Isolation. The remainder of this section describes some of these attributes in the design of the program:

The Structure of the Program: The program at Robert Morris University is designed so that students enrolled in it can complete it within six semesters (or three years). The structural enforcement mechanisms include a "lock step" cohort approach in which all students admitted at the same time take the same courses together in the same sequence. The students must take the 3 
specific courses each semester in order to proceed to the next semester. This facilitates the progression of students from one semester to the next.

The Residency Weeks/Weekends: This program is held during mandatory residency periods. Each of the six terms has a scheduled residency week and 3 residency weekends. The students stay at a nearby hotel and logistics are taken care of by RMU staff. The residencies are tightly scheduled with classes and one-on-one faculty-student meetings and break time to allow for both formal and informal discussion. Having a dedicated scheduled time helps with student-to-student and student-to-faculty communications.

The Cohort Enrollment Approach: In this approach, students start the program as one group (cohort), then take courses at the same time and move to complete the program together. Entering a program with a particular group of students, and taking courses with the same students helps to reduce the feeling of isolation. Moreover, the content of the doctoral program at RMU include additional activities that help breaking isolation among the students themselves and also among the students and faculty alike.

\section{SUMMARY}

This paper supports what was found in the literature that isolation feeling among doctoral students play significant role in the attrition rate. The paper further suggested that isolation could be dealt with by incorporating program design characteristics that encourages communications at two fronts: Student-to-student communications and student-to-faculty communication. The doctoral program at Robert Morris University made such incorporation in their design and have been able to achieve a graduation rate that is substantially higher than the national average.

\section{REFERENCES}

1. Bourner, T., Bowden, R. \& Laing, S. (2001). Professional doctorates in England. Studies in Higher Education, 26, 1. Retrieved February 18, 2004 from EBSCOHost.

2. Lovitts, B. E. (2001). Leaving the ivory tower: The causes and consequences of departure from doctoral study. Lanham, MD: Rowman \& Little Field Publishers.

3. Lovitts, B. E. \& Nelson, C. (2005). The Hidden Crisis in Graduate Education: Attrition from Ph.D Programs. Retrieved January 27, 2005 from http://www.aaup.org/publications/academe/2000/00nd/ND00LOVI.HTM

4. Powers, L. (2004). Doctoral Dilelmma: Half of all Ph.D. Candidates Drop Out, Wasting Resources. Reno Gazette-Journal October 29, 2004. Retrieved November 15, 2004 from http://www.rgj.com/news/stories/html/2004/10/29/84016.php. 